\title{
EVALUATION OF ERGONOMICS' AWARENESS AMONG A GROUP OF EGYPTIAN DENTAL INTERNS
}

\author{
Norhan A El Dokky and Dalia M Moheb
}

\begin{abstract}
Dentistry is a profession associated with several occupational hazards. Ergonomic is the science dealing with people and their working environment. Evaluation of ergonomics' awareness is minimal among dentists. Aim: To evaluate interns' awareness level of concepts of ergo-dynamics.

Subjects and Methods: This cross-sectional study was conducted on 40 interns in Faculty of Dentistry- Cairo University. Self- structured questionnaire, which addressed demographic data and average daily working hours was utilized. The participants' awareness of ergo-dynamics was evaluated, and if participants adopted these principles in daily practice. The study evaluated if participants believed that applying such concepts was important, and whether these concepts should be part of dental curricula. Moreover, the study investigated if participants suffered from back and / or neck pain. Statistical analysis used: Data were gathered and expressed as percentages.
\end{abstract}

Results: The study was conducted on 19 females (47.5\%) and 21 males (52.5\%). Participants worked in an average of 6-8 hours daily. The data revealed that $62.5 \%$ of participants never heard about ergonomics and only $37.5 \%$ heard about them from internet and their supervisors. $95 \%$ of them believed these concepts were important and that they must be part of dental curricula. $82 \%$ of participants were not aware of best distance from instruments \& $70 \%$ of them didn't know correct sitting postures. $90 \%$ of participants suffered back and/or neck pain.

Conclusion: There is substantial lack of awareness about ergonomics among the studied group, despite the positive attitude towards studying and applying ergonomics' principles.

KEY WORDS: Awareness, dental interns, ergonomics, occupational hazards.

\section{INTRODUCTION}

Ergonomic is the science dealing with people and their working environment done to improve effectiveness (1). "Ergo" in Greek is work, and "Nomic" is the natural law or system ${ }^{(2)}$. According to the International Ergonomics Association:" it is the scientific practice aiming to correlate between humans and other elements of a system, profession, and methods to design workplace to optimize human well-being and system performance" ${ }^{(3)}$.

Dentistry is a profession associated with several occupational hazards and disorders like 
musculoskeletal pain and soreness, which are usually ignored until they become chronic and permanent (4). This have been reported widely among most of the dental teams including dental students ${ }^{(5)}$. Among the ergonomic risk factors that can hamper the dental work include: extended working hours, forceful work, prolonged static work in wrong postures and unsupported sitting ${ }^{(6)}$.

Back pain is the most widely common occupational hazard among dentists, next is the neck pain, muscle tension, tendinitis, nerve trapping, arthrosis, myopia, and adaptive alterations (7). Some previously conducted studies revealed that about $62 \%$ of dental practitioners suffer from musculoskeletal disorder, ranging from discomfort and sporadic pain to functional restrictions and loss of working ability ${ }^{(8-10)}$.

Moreover, technological advances in dentistry could lead to higher workload among dentists, although such advances can make dental work simpler and easier, they frequently neglect the role of posture in routine dental work, leading to increased number of complaints specifically musculoskeletal disorders ${ }^{(11-12)}$, resulting in decrease of the working capability of the dental practitioners ${ }^{(13)}$.

A recent study reported that from 189 retired dentists, the common reason for retirement in $55 \%$ was musculoskeletal disorders ${ }^{(14)}$.

Therefore, applying dental ergonomics can improve the quality of work making it easier, faster and safer, consequently increasing productivity and maintaining better quality of life for dental professionals ${ }^{(15)}$.

Several studies revealed contradicting results regarding knowledge and awareness of dental professionals about ergonomics worldwide ${ }^{(16)}$. The need increases to include ergonomics' principles in the curricula of all dental schools ${ }^{(17)}$.

In Egypt there is deficiency in studies assessing this increasing problem, so the current study was carried out with the aim of evaluation of the level of awareness of dental ergonomics among a group of dental interns in Faculty of Dentistry, Cairo University.

\section{SUBJECTS AND METHODS}

This is a cross-sectional and qualitative study. The study was conducted on 40 interns in Faculty of Dentistry- Cairo University. The study was carried out in accordance with the ethical guidelines in research with human participants and approved by the Research Ethics Committee of Faculty of Dentistry- Cairo University (code17-10-14).

A questionnaire composed of 22 questions was designed by the investigators to evaluate the level of awareness of a group of interns regarding ergonomics.

The questionnaire comprised close ended as well as open ended question and was self- administered to the study participants. Subjects were asked to respond to each item according to response format. Subjects received full explanation of how to score their responses and were made fully aware regarding responses. The purpose of the study was explained to the interns.

The questionnaire consisted of questions to obtain demographic data, number of working hours, awareness regarding concepts of ergonomics, presence or absence of pain, importance of ergonomics, using loupes for magnification, performing stretching exercises between patients, maintaining correct posture during working, having a dental assistant and whether ergonomics should be integrated in dental curricula for undergraduate students.

Upon completion, data was gathered, expressed as percentages and analyzed. All statistical calculations were done using computer program SPSS (Statistical Package for the Social Science; SPSS Inc., Chicago, IL, USA) version 15 for Microsoft Windows 


\section{RESULTS}

The participants independently filled out the questionnaire. The questionnaire was distributed and collected on the same day. The respondents were kept anonymous. A total of 40 dental interns comprised the study. $100 \%$ response rate was achieved.

Gender: The questionnaire was completed by a total of 19 females $(47.5 \%)$ and 21 males $(52.5 \%)$ dental interns.

35 participants $(87.5 \%)$ were single and only $5(12.5 \%)$ of them were married and the age of studied participants ranged from 22-26 years, their mean age was 24 years.

The main aspects covered in the questionnaire are presented in collective points as follows:

\section{1) Adopting Ergonomics' principles:}

$62.5 \%$ of the studied sample; thought they adopted ergonomics' principles, $10 \%$ didn't try to, $25 \%$ had no information about the matter, while $2.5 \%$ responded that they did not really care to adopt such principles as shown in figure (1).

An open-ended question about why they thought this was important was answered with reasons like: avoiding pain-having better working environment and making work easier.

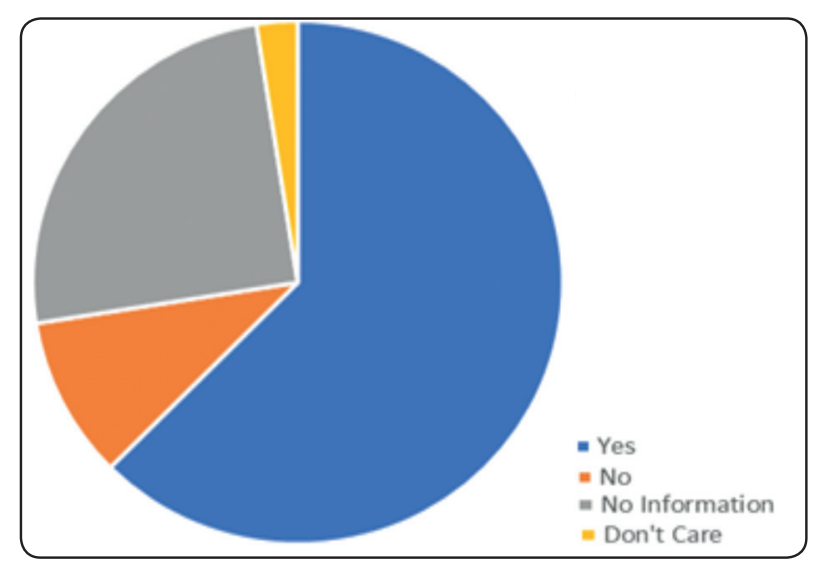

Fig. (1): Adopting Ergonomics principles

\section{2) Whether dentists should follow ergonomics in routine dental practice:}

$87.5 \%$ reported their acceptance, while $12.5 \%$ did not.

\section{3) Is it important to adopt ergonomics?}

$95 \%$ of the studied sample believed in the importance of ergonomics, while 5\% did not really care, however, none of the studied sample rejected the importance of adopting ergonomics.

In an open-ended inquiry, the reasons provided were to avoid pain\& fatigue.

\section{4) Adopting proper postures by colleagues:}

According to the study, $35 \%$ claimed that their colleagues do, whereas, $22.5 \%$ claimed they did not, and $42.5 \%$ didn't seem to notice as shown in figure (2).

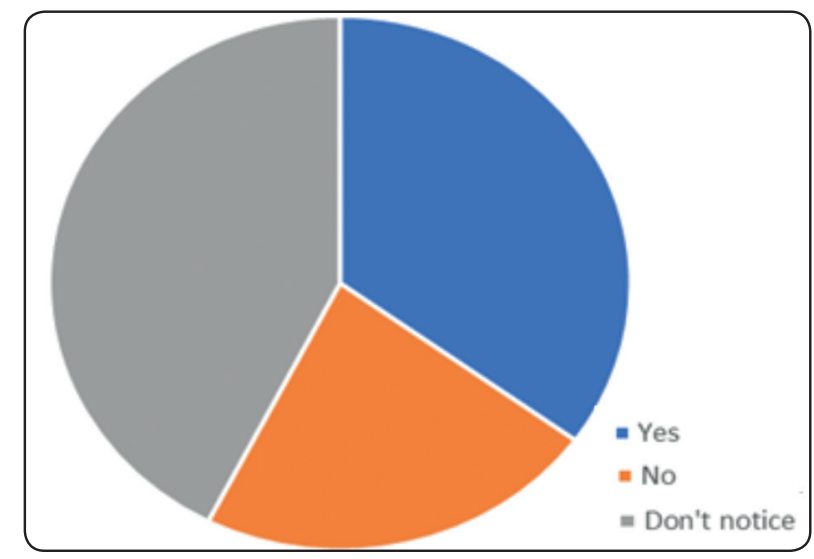

Fig. (2): Adopting proper postures by colleagues

\section{5) Prior knowledge about ergonomics:}

$37.5 \%$ of the studied sample indicated that they had previous information, while $62.5 \%$ were not exposed to such concepts before as shown in figure (3). Internet and supervisors were the main sources of prior knowledge as indicated in an open-ended inquiry. 


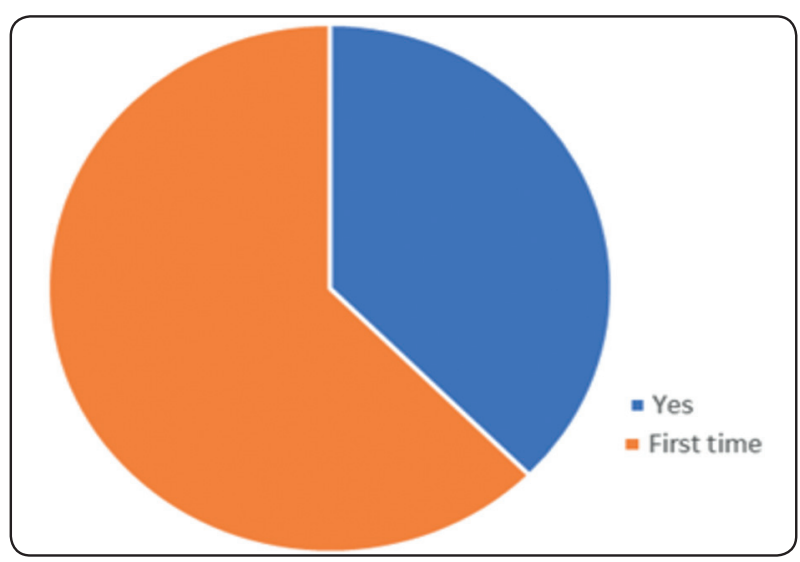

Fig. (3): Prior knowledge about ergonomics

6) Ergonomics as part of dental curricula: in the present study (95\%) agreed that ergonomics should be integrated in dental curricula, $(2.5 \%)$ did not agree and $(2.5 \%)$ did not really care as shown in figure (4).

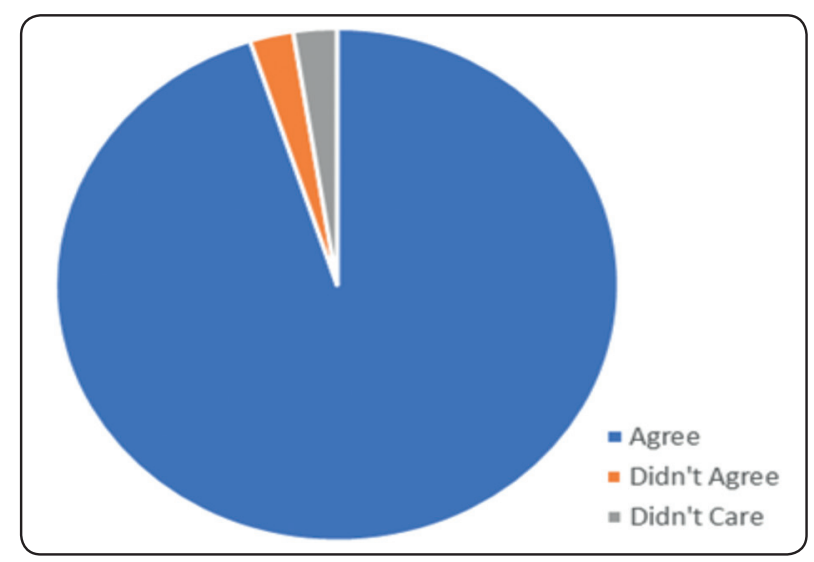

Fig. (4): Ergonomics as part of dental curricula

\section{7) Working hours:}

Results of the current study showed that average daily working hours of the included dental interns were 6-8hours.

\section{8) Standing and sitting between appointments:}

$60 \%$ indicated they knew they should, while $40 \%$ didn't know if they should however, none of the studied sample disagreed.

\section{9) Stretching exercises:}

$50 \%$ indicated that they performed stretching exercises between patients, and $50 \%$ did not.

10) All the participants approved that dental chair and instruments play role in following proper ergonomic principles.

11) According to the study $67.5 \%$ knew the ideal sitting angle, and $32.5 \%$ did not seem to know, regarding the depth and width of the seat $25 \%$ knew, $72.5 \%$ did not, while $2.5 \%$ did not really care. In addition, $30 \%$ knew the ideal sitting postures, $65 \%$ did not know, and 5\% did not care.

\section{2) Instruments and dentist:}

$17.5 \%$ knew the correct distance between instruments and dentist, while $82.5 \%$ did not know.

\section{3) Patient positions:}

The current study revealed that $35 \%$ of the studied sample knew the ideal sitting positions of patients, $60 \%$ did not know, and 5\% did not really care, (figure 5).

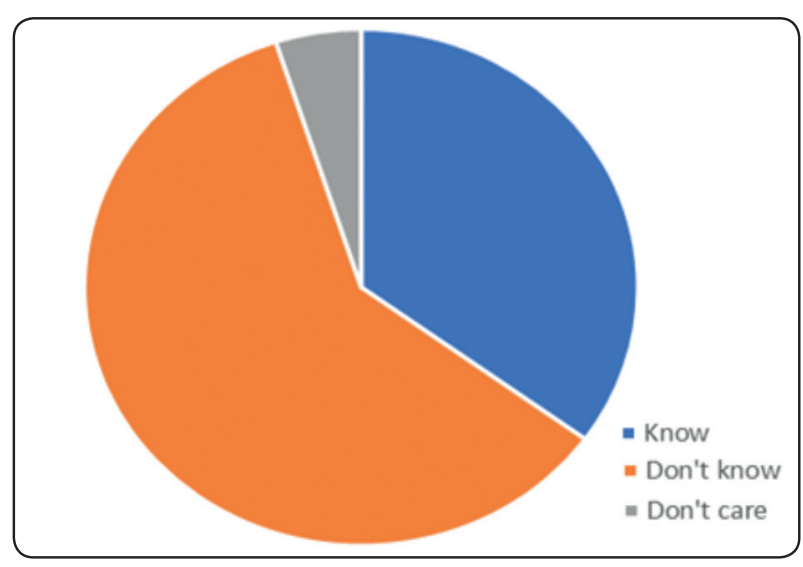

Fig. (5): Patients' position

\section{4) Use of loupes:}

Only $10 \%$ indicated that they used loupes, while 90\% did not use them. 


\section{5) Availability of assistants:}

$60 \%$ of the participants had a dental assistant, while $40 \%$ did not as shown in figure (6).

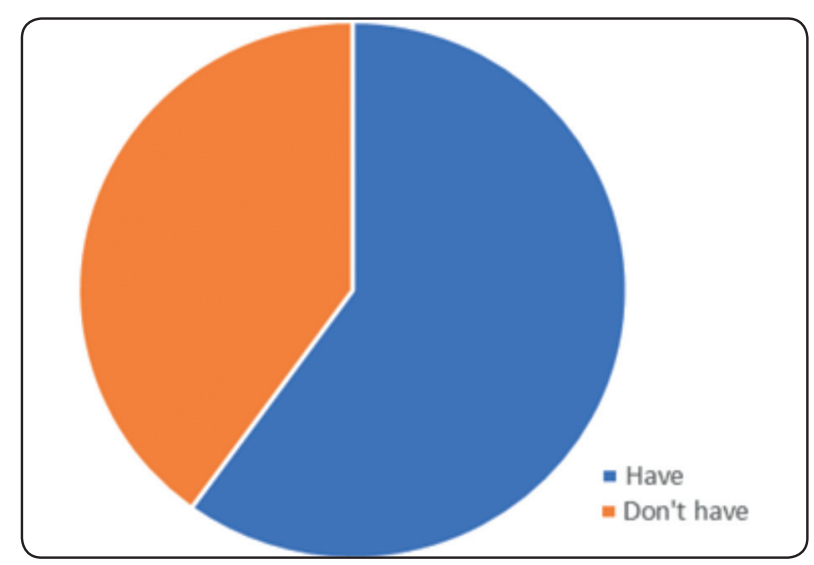

Fig. (6): Availability of assistants

\section{6) Postures:}

$32 \%$ of participants indicated that they adopted inappropriate postures as: bending- leaning - not sitting upright.

\section{7) Suffering from pain:}

As regard pain (90\%) reported to suffer from pain, $44.4 \%$ experienced back pain, $14.3 \%$ experienced neck pain, $41.6 \%$ suffered from both, and $10 \%$ were free from pain as shown in figure (7).

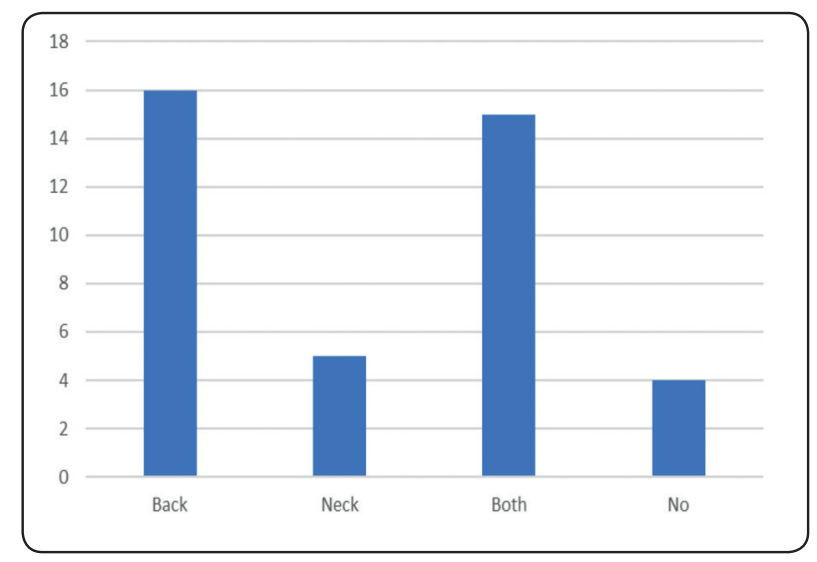

Fig. (7): Suffering from pain

\section{DISCUSSION}

The level of ergonomics' awareness is thought to be minimal among dentists in India and China, regarding the knowledge and practice during clinical work ${ }^{(2,8)}$. Moreover, ergonomics is not a part of the dental curricula of many courses for both undergraduate and postgraduate levels.

In Egypt the data about ergonomics is scarce, so this cross-sectional study was carried out to evaluate the awareness level of dental ergonomics among a group of Egyptian dental interns in Faculty of Dentistry- Cairo University.

In the present study all the dentists responded to the questionnaire, this high response rate may be due to handling the questionnaire to the dentists in person and not by mail, this comes in agreement with Desai et al; $2012^{(18)}$.

According to the results of the current study it was found that high percentage of interns (95\%) believed in the importance of the concepts of ergonomics, this goes in agreement with Mailoa \& Rovani $2011{ }^{(19)}$ and El-Sallamy et al; 2017 (17), this may be due to receiving information about ergonomics from internet and supervisors during clinical work, on the contrary these results disagree with results of study conducted by Madaan and Chaudhari 2012, which showed lower scores of awareness $(19 \%)^{(20)}$. In addition, $87.5 \%$ accepted to follow ergonomics during routine dental work, referring to its importance in reducing pain and fatigue.

More than half $(62.5 \%)$ of the studied sample thought that they adopt ergonomics principles during their routine work, on contradiction to this result more than half $(62.5 \%)$ of them had no previous knowledge about ergonomics, this is in accordance with Diaz-Caballero et al; 2010, who reported that this may be due to not integrating ergonomics in syllabus of dental schools and the knowledge is disseminated by informal means ${ }^{(4)}$, in the present 
study the internet and supervisors were the source of knowledge.

As regards the average working hours per day the results of the present study (which is 6-8 hours) were close to that of Barlean et al; 2012 who revealed that the dentists in his study declared that they work from 4-7 hours and part of them work 7 hours/day ${ }^{(21)}$ and in agreement with El-Sallamy et al; 2017 where $60 \%$ of the dentists worked for 6 hours/day ${ }^{(17)}$.

Most of the questions that were included in the current study aimed to evaluate the experiences, attitudes and awareness of the dental interns in relation to ergonomics, this may lead them to feel intimidated in expressing their thoughts, as they are in educational environment and they feel they are permanently evaluated, so question 4 was included to ask them about their colleagues who are in similar situation, this approach comes in accordance with Garcia et al; $2017^{(22)}$. High percentage (42.5\%) of the dentists didn't notice their colleagues, while $(35 \%)$ claimed that their colleagues adopt proper posture, while (22.5\%) thought they didn't adopt ergonomics this result may be due to that great emphasis is given to the technical rather than occupational hazards related to promotion of health, this comes in accordance with Mialhe and Silva; 2011, ${ }^{(23)}$.

In the present study $95 \%$ of the participating dental interns agreed about integrating ergonomics in dental curricula this goes in agreement with Vyas et al; 2014 to avoid major occupational hazards problems ${ }^{(24)}$, and El-Sallamy et al; 2017 who stated that $69.1 \%$ thought that ergonomics should be integrated in dental curricula ${ }^{(17)}$.

The results of the current study indicated that more than half $(60 \%)$ knew that they should stand between the appointments, while the rest didn't know, this goes in accordance with Desai et al; $2012^{(18)}$, however this disagrees with Garbin et al; 2015, who revealed that about $86 \%$ of the dentists stated that they don't rest between appointments ${ }^{(25)}$. Moreover, half of the interns performed stretching exercises and the other half didn't, this may provide dentists with break from excessive workload, and strengthen their bodies in addition to providing mental relaxation ${ }^{(26)}$.

According to the results of the present study all the dentists approved that dental chair and instruments play major role in adopting ergonomics' principles, this disagrees with El-Sallamy et al; 2017 who revealed that only $56.4 \%$ thought that dental chair and instruments play a role in adopting ergonomics during dental work ${ }^{(17)}$. More than half of the studied sample $(67.5 \%)$ knew the ideal sitting angle, while $72.5 \%$ didn't know the depth of chair, $65 \%$ didn't know the ideal sitting posture, more than half $(60 \%)$ of the interns didn't know the ideal position of the patient, and $82.5 \%$ didn't know the ideal distance between the dentist and the instruments, these results disagree with Barlean et al; 2012 and Madaan and Chaudhari; 2012, who revealed that half of the dentists had fair knowledge ${ }^{(20,21)}$, this could be attributed to lack of ergonomics principles in our curricula.

Most of the dentists (90\%) in the study didn't use loupes, this result nearly goes in accordance with Desai et al; 2012 who reported that $70 \%$ didn't use loupes, this could be attributed to young age of the interns and they are just starting their clinical practice as well as extra expenses needed to use loupes ${ }^{(18)}$.

The results of current study revealed that $60 \%$ of the interns had a dental assistant this agrees with Barlean et al; 2012 this may be done to increase productivity and reduce fatigue and stress ${ }^{(21)}$.

One third of the interns admitted that they adopt inappropriate postures during working, this agrees with Gabrin et al; 2011, this may be due to feeling uncomfortable in the correct position, lack of attention, and difficulty in visualizing the operatory field or the procedure performed ${ }^{(27)}$. 
Finally, $90 \%$ of the dental interns said they suffered from pain. Ranging from back pain, neck pain or both, this comes in accordance with Desai et al; 2012 who revealed that $85 \%$ of the dentists reported muscular pain ${ }^{(18)}$, Garbin et al; 2015, also concluded that $65.6 \%$ suffered from pain ${ }^{(25)}$, this was attributed to time spent sitting down for working, wrong posture during working and not exercising between patients ${ }^{(25)}$.

\section{CONCLUSIONS}

There is substantial lack of awareness about ergonomics among the studied group, but they have positive attitude towards studying and applying ergonomics' principles.

\section{RECOMMENDATIONS}

1) Ergonomic concepts should be part of undergraduate dental curricula to improve awareness level, along with practical implication during different dental procedures.

2) More studies are needed on larger scale in governmental and private dental schools to evaluate the awareness of their students.

\section{REFERENCES}

1. Cambridge advanced learner's dictionary and thesaurus. Cambridge University Press.

2. Kalaghatgi SR, Prasad KVV, Chhbara KG, Deolia S, Chhabra C. Insights into ergonomics among dental professionals of a dental institute and the private practitioners in Hubli- Dharwar twin cities, India. Elsevier Science Safety and Health at work 2014; 5: 181-85.

3. Lehto TU, Helenius HY, Alaranta HT. Musculoskeletal symptoms of dentists assessed by a multidisciplinary approach. Comm Dent Oral Epidemiol 1991; 19: 38-44.

4. Diaz- Caballero AJ, Gomez-Palencia IP, Diaz- Cardenas S. Ergonomic factors that cause the presence of pain muscle in students of dentistry. Med Oral Patol Oral Cir Bucal 2010; 15: 906-11.
5. Rucker LM, Sunell S. Ergonomic risk factors associated with clinical dentistry. J Clif Dent Assoc 2002; 30: 139-48.

6. Leggat PA, Kedjarune U. Occupational risks of modern dentistry: A review. J Occup Health Saf (Aust NZ) 2001; 17: 279-86.

7. Yousef MK, Al-Zain AO. Posture evaluation of dental students. JKAU Med Sci 2009; 16: 51-68.

8. Alexopoulos EC, Stathi IC, Charizani F. Prevalence of musculoskeletal disorders in dentists BMC Musculoskeletal Disorders 2004; 5: 16- 21.

9. Kierklo A, Kobus A, Jaworska M, Botulinski B. Work related musculoskeletal disorders among dentists- A questionnaire survey. Ann Agric Environ Med 2011; 18:79-84.

10. Kar G, Mullick A. Designing with users: A case study for design of dental workspace. Proceedings of the Human Factors and Ergonomics Society 2012; 652-55.

11. Pinto ACCS. Laboral physical exercise applied to health of dental surgeon: a study at Secretaria Municipal de Florianopolis- SC. Florianopolis: Universiade Federal de Santa Catarina 2003.

12. Sales Peres A, Paschoarelli LC, Silva RHA, Kushima F. Technological interface in the dentists' professional activities: ergonomics design boarding. Rev Fac Odontol Aracatuba 2005; 26:44-48.

13. Lydia G, Ivan I, Marin I, Kalina P. Ergonomization of the working environment and building up of healthy working posture of dental students' of IMAB 2012 18:243-50.

14. Brown J, Burke F, Macdonald E, Gilmour H, Hill K, Morris A et al. Dental practitioners and ill health retirement causes, outcomes and re-employment. Br Dent J 2010; 209: E7.

15. Corrocher PA, Presoto CD, Campos JABD, Garcia PPNS. The association between restorative pre-clinical activities and musculoskeletal disorders. Eur J Dent Educ 2014; 18: 142- 46.

16. Karibasappa GN, Sujatha A, Rajeshwari K. Dentists' Knowledge, attitude and behavior towards the dental ergonomics. J Dent \& Medical Sci 2014; 13: 86-89.

17. El-Sallamy RM, Atlam SA, Kabbash I, Abd El- Fattah S, El- Flaky A. Knowledge, attitude, and practice towards ergonomics among undergraduates of Faculty of Dentistry, Tanta University, Egypt. Environ Sci Pollut Res Int 2017; doi:10.1007/s 11356-017-8615-3. 
18. Desai V, Pratik P, Sharma R. Ergonomics: A must for dentistry: A cross sectional study in various parts of Northern India. www.journaloddentofacialsciences.com 2012 1: 1-5.

19. Mailoa PR, Rovani P. Study of ergonomic aspect dentistry of some private dental clinic in Makassar: Hasanuddin University; Makassar (Indonesia): http://respiratory.unhas. ac.id/handle/123456789/689 (Internet) 2011.

20. Madaan V, Chaudhari A. A prevalence and risk factor associated with musculoskeletal pain among students of MGM dental college: a cross-sectional survey. J Contemp Dent Pract 2012; 2:22-27.

21. Barlean L, Danila I, Saveanu I. Dentists ergonomics and attitudes in North-est region, Romania. Roman J Oral Rehab 2012; 4:40-43.

22. Garcia PPNS, Gotttardello ACA, Wajngarten D, Presto $\mathrm{CD}$, Campos ADB. Ergonomics in dentistry: experiences of the practice by dental students. European J Dent Educ 2017;21: 175-79.
23. Mialhe FL, Silva CM.Health education and their representations among dental students. Cien Saude Colet 2011; 16: 1555-61.

24. Vyas K, Parihaar L, Rajoria K, Pandit A, Singh J. Knowledge, attitude and behavior towards "Ergonomics" among oral health professionals in Jodhpur city, Rajasthan, India. J Pre Clin Dent Res 2014; 1: 5-9.

25. Garbin AJI, Garbin CAS, Arcieri RM, Rovida TAS, Friere ACF. Musculoskeletal pain and ergonomic aspects of dentistry. Rev Dor. Sao Paulo2015; 16: 90-95.

26. Hildebrandt VH, Bongers PM, Dul J, et al:: The relationship between leisure time, physical activities and musculoskeletal symptoms and disability in worker populations. Int Arch Occup Environ Health 2000; 73: 507-18.

27. Garbin AJI, Garbin CAS, Diniz DG, Yarid SD. Dental students' knowledge of ergonomic postural requirements and their application during clinical care. European J Dent Educ2011; 15: 31-35 